Nova Southeastern University

Florida

NOVA SOUTHEASTERN

UNIVERSITY

NSUWorks

Marine \& Environmental Sciences Faculty Articles Department of Marine and Environmental Sciences

6-1-1994

\title{
Parameterization of the Cool Skin of the Ocean and of the Air-Ocean Gas Transfer on the Basis of Modeling Surface Renewal
}

Alexander Soloviev

Russian Academy of Sciences - Moscow, soloviev@nova.edu

Peter Schlüssel

Universität Hamburg - Germany

Find out more information about Nova Southeastern University and the Halmos College of Natural Sciences and Oceanography.

Follow this and additional works at: https://nsuworks.nova.edu/occ_facarticles

Part of the Marine Biology Commons, and the Oceanography and Atmospheric Sciences and Meteorology Commons

\section{NSUWorks Citation}

Alexander Soloviev and Peter Schlüssel. 1994. Parameterization of the Cool Skin of the Ocean and of the Air-Ocean Gas Transfer on the Basis of Modeling Surface Renewal .Journal of Physical Oceanography , (6) : 1339 -1346. https://nsuworks.nova.edu/ occ_facarticles/628.

This Article is brought to you for free and open access by the Department of Marine and Environmental Sciences at NSUWorks. It has been accepted for inclusion in Marine \& Environmental Sciences Faculty Articles by an authorized administrator of NSUWorks. For more information, please contact nsuworks@nova.edu. 


\title{
Parameterization of the Cool Skin of the Ocean and of the Air-Ocean Gas Transfer on the Basis of Modeling Surface Renewal
}

\author{
ALEXANDER V. SOLOVIEV \\ P.P. Shirshov Institute of Oceanology, Russian Academy of Sciences, Moscow, Russia \\ Peter SCHLÚSSEL \\ Universität Hamburg, Meteorologisches Institut, Hamburg, Germany \\ (Manuscript received 4 February 1992, in final form 12 October 1993)
}

\begin{abstract}
Heat and gas transport in molecular sublayers at the air-sea interface is governed by similar laws. A model of renewal type based on the physics of molecular sublayers allows the derivation of a parameterization of the temperature difference across the cool skin of the ocean and of the coefficient of the direct air-sea gas transfer. The surface Richardson number controls the transition from convective instability to wind-induced instability ("rollers" on breaking wavelets) and the Keulegan number controls the transition from the regime of rollers to long-wave breaking. A critical value of the surface Richardson number and of a nondimensional constant can be evaluated by comparing the parameterizations of the cool skin with field data. The critical value of the Keulegan number is determined from the wind speed at which long-wave breaking appears. The parameterizations have been compared with cool skin data obtained from campaigns in the tropical and subtropical Atlantic Ocean, while the gas transfer data are compiled from several experiments in the global ocean. The cool skin data have been used for an adjustment of the parameterization of the direct gas transfer. The parameterization does not include effects of bubble and droplet production in whitecaps, which can be important at high wind speed conditions.
\end{abstract}

\section{Introduction}

Damping of turbulence by the air-sea interface results in a formation of molecular sublayers adjacent to the interface. Viscous, thermal, and diffusion sublayers all occur adjacent to the sea surface. Surface stresses, surface waves, and buoyancy forces influence the turbulent mixing near the surface and, therefore, the thickness of the molecular sublayers.

The viscous sublayer of the ocean is of order $1 \mathrm{~mm}$ thick (Wu 1975; McLeish and Putland 1975; Wu 1984). Near the upper boundary of the viscous sublayer, thermal (Saunders 1967; Hasse 1971; Grassl 1976; Katsaros et al. 1977; Paulson and Simpson 1981; Schluessel et al. 1990) and diffusion (Bolin 1960; Hasse and Liss 1980; Jähne et al. 1987; Csanady 1990) sublayers exist. The former is also called the cool skin of the ocean.

For the mean temperature difference $\Delta \bar{T}$ across the cool skin of the ocean, Saunders (1967) proposed the relationship,

Corresponding author address: Dr. Peter Schlüssel, Meteorologisches Institut, Universität Hamburg, Bundesstrasse 55, D-20146 Hamburg, Germany.

$$
\Delta \bar{T}=-\frac{\lambda(\nu / \kappa) Q_{0}}{u_{*} c_{p} \rho},
$$

where $Q_{0}$ is the heat flux just below the sea surface ( $Q_{0}$ $<0) ; \nu$ and $\kappa$ are the coefficients of molecular viscosity and thermal diffusion, respectively; $u_{*}$ is the friction velocity in the upper ocean; $c_{p}$ is the specific heat capacity; and $\rho$ is the water density. According to Saunders (1967) $\lambda$ varies between 5 and 10 except for conditions with light wind and intense solar insolation. For calm weather conditions Katsaros et al. (1977) used the following relationship:

$$
\Delta \bar{T}=b\left(\alpha g \kappa^{2} / \nu\right)^{-1 / 4}\left(-Q_{0} / c_{p} \rho\right)^{3 / 4},
$$

where $\alpha$ is the coefficient of thermal expansion of water, $g$ the acceleration of gravity, and $b$ a nondimensional coefficient. Csanady (1990) derived a formula for the gas transfer coefficient,

$$
K=\gamma \mathrm{Sc}^{-1 / 2} u_{*},
$$

where Sc $=\nu / \mu$ is the Schmidt number, $\mu$ is the coefficient of molecular gas diffusion, and $\gamma$ is a nondimensional constant.

The thermal sublayer in the upper ocean does not substantially affect the heat exchange between ocean and atmosphere and, therefore, plays a passive role 
(Paulson and Simpson 1981). At the same time, airsea gas transport substantially depends on parameters of the oceanic diffusion sublayer. Due to low gas diffusivity in water compared to the rather high gas diffusivity in air the diffusion sublayer provides the main resistance to atmosphere-ocean gas transport (Bolin 1960).

Despite different roles in the heat and gas exchange at the air-sea interface, the thermal and diffusion sublayers of the ocean are governed by similar laws. The aim of this paper is to develop a universal parameterization of the thermal and diffusion sublayers that is valid for a wide range of wind speeds. The readily available cool skin data can then be used for an adjustment of the gas transfer parameterization.

\section{Dimensional analysis}

Here we ignore bubble and droplet production in white caps and hence consider only the direct heat and gas fluxes at the air-sea interface. In the case of stationary weather and wave conditions, one can expect the temperature difference across the cool skin of the ocean, $\Delta \bar{T}$, and the gas transfer coefficient, $K$, as follows:

$$
\begin{aligned}
\Delta \bar{T} & =\text { function }_{T}\left(u_{*}, q_{0}, \alpha, g, \nu, \mu, \kappa, H\right), \\
K & =\text { function }_{G}\left(u_{*}, q_{0}, \alpha, g, \nu, \mu, \kappa, H\right),
\end{aligned}
$$

where $q_{0}=-Q_{0} / c_{p} \rho, Q_{0}$ is the vertical heat flux at the sea surface due to latent and sensible heat fluxes as well as net longwave radiation flux, and $H$ is the depth of the upper-ocean mixed layer. Relations (4) and (5) take into account the influence of thermally driven convection, wind-induced turbulence, and gravity waves on the molecular sublayers. Relations (4) and (5) do not contain, however, the solar radiation flux. In the near-surface water the solar radiation is a volume source of heat and does not directly affect the molecular sublayers (excluding conditions of strong solar insolation near local noon time) (Soloviev 1987).

A standard dimensional analysis of (4) and (5) leads to the following relations:

$$
\begin{aligned}
\Delta \bar{T} / T_{*} & =f_{T}\left(R f_{0}, \mathrm{Sc}, \mathrm{Pr}, \mathrm{Ke}, \mathrm{Ra}_{H}\right), \\
K^{+} & =f_{G}\left(R f_{0}, \mathrm{Sc}, \operatorname{Pr}, \mathrm{Ke}, \mathrm{Ra}_{H}\right),
\end{aligned}
$$

where $T_{*}=q_{0} / u_{*}, K^{+}=K / u_{*}, f_{T}$, and $f_{G}$ are nondimensional functions and their nondimensional arguments $R f_{0}=-\alpha g q_{0} \nu / u_{*}^{4}, \mathrm{Sc}=\nu / \mu, \operatorname{Pr}=\nu / \kappa, \mathrm{Ke}$ $=u_{*}^{3} / g \nu$, and $\mathrm{Ra}_{H}=\alpha g q_{0} H^{4} / \nu \kappa^{2}$.

In the upper ocean the global Rayleigh Number $\left(\mathrm{Ra}_{H}\right)$ is usually very large. It is well known from the theory of turbulence that, in a fully developed turbulent flow, parameters of a boundary molecular sublayer no longer explicitly depend upon the external scale of the flow. In particular, Foster (1971) showed that, for large values of convective layer, thickness parameters of the surface molecular sublayer do not depend upon $H$. Hence one may assume here a hypothesis of self-similarity on the $\mathrm{Ra}_{H}$ number. Consequently $\mathrm{Ra}_{H}$ drops out of number of the determinant parameters and (6) and (7) reduce to

$$
\begin{aligned}
\Delta \bar{T} / T_{*} & =F_{T}\left(R f_{0}, \mathrm{Sc}, \mathrm{Pr}, \mathrm{Ke}\right), \\
K^{+} & =F_{G}\left(R f_{0}, \mathrm{Sc}, \mathrm{Pr}, \mathrm{Ke}\right),
\end{aligned}
$$

where $F_{T}$ and $F_{G}$ are universal functions.

The parameter $R f_{0}$ can be identified as a surface Richardson number. From the definition of the Richardson number, $R f=\alpha g q_{0} \rho /(\tau d u / d z)$, in the nearsurface layer of the ocean and from the relation for the momentum flux, $\tau=-\rho \nu d u / d z$, within the viscous sublayer one can derive the following relation:

$$
R f\left(z<\overline{\delta_{v}}\right)=-\alpha g q_{0} \nu / u_{*}^{4}=R f_{0},
$$

where $d u / d z$ is the shear in the boundary-layer current, $\bar{\delta}_{v}$ is the thickness of the viscous sublayer, and $\tau$ $=\rho u_{*}^{2}$. The nondimensional number $R f_{0}$ can hence be named the "surface Richardson number" (Kudryavtsev and Soloviev 1985). The nondimensional parameters Sc, Pr, and Ke are the Schmidt, the Prandtl, and the Keulegan numbers, respectively (see Csanady 1978 ). Elucidation of dependencies ( 8 ) and (9) is possible within the framework of a physical model of the molecular sublayers.

\section{Renewal model}

There have been many previous studies relevant to modeling molecular sublayers. Kim et al. (1971) observed that the turbulent momentum transport and production in the wall layer takes place intermittently in time and space through small-scale bursting motions. Liu and Businger (1975) developed a method for calculation of temperature profiles in molecular sublayers by assuming that the sublayers undergo cyclic growth and destruction. Kudryavtsev and Luchnik (1979) and Kudryavtsev and Soloviev (1981) described the transition from free to forced convection in the near-surface ocean. Later Kudryavtsev and Soloviev (1985) derived a parameterization of the temperature difference across the thermal molecular sublayer at low and moderate wind speeds. Laboratory measurements at Tohoku University by Toba and his colleagues (Toba 1985; Ebuchi et al. 1987; Okuda 1982) revealed the important role of breaking wavelets in the water renewal at free surfaces. Recently, Csanady (1990) carried out a fine study elucidating the role of the rollers in air-sea gas transfer. Soloviev (1991) derived a parameterization of the oceanic molecular sublayers at low, moderate, and high wind speed conditions. The aforementioned studies allow us to develop a model of renewal type based on the physics of molecular sublayers and to derive parameterizations for both the temperature dif- 
ference across the cool skin of the ocean and air-sea gas transfer.

Following Liu and Businger (1975), we consider a fluid element adjacent to the sea surface. Initially it has a uniform temperature and concentration of scalar property equal to the bulk-water values. As it is exposed to the interface, the surface flux $\left(G_{0}\right)$ of a scalar property $C$ and the temperature difference $(\Delta T)$ across the thermal sublayer are governed by the appropriate molecular diffusion laws [at constant concentration difference $(\Delta C)$ and at constant heat flux $\left(q_{0}\right)$, respectively ]:

$$
\begin{aligned}
G_{0}(t) & =\pi^{-1 / 2}(t / \mu)^{-1 / 2} \Delta C \quad \text { and } \\
\Delta T(t) & =2 \pi^{-1 / 2}(t / \kappa)^{1 / 2} q_{0},
\end{aligned}
$$

where $\pi=3.14$.

The vertical flux of heat just below the sea surface is usually upward and equal to the sum of the flux to the atmosphere of sensible heat $\left(Q_{T}\right)$, latent heat $\left(Q_{L}\right)$, and net longwave radiation $\left(Q_{E}\right)$; that is, $-c_{p} \rho q_{0}$ $=-\left(Q_{T}+Q_{L}+Q_{E}\right)$ where we neglect the effect of solar radiation because it is a volume source of heat. Because values of $Q_{L}$ and $Q_{E}$ do not markedly depend upon the temperature difference across the cool skin (Paulson and Simpson 1981) and usually $\left|Q_{L}+Q_{E}\right|$ $\gg\left|Q_{T}\right|$, the condition of constant heat flux is more appropriate for the description of the cool skin than that of constant temperature difference. At the same time, the condition of constant concentration difference follows from the fact that the water diffusion sublayer provides the main resistance to the air-sea gas transfer (Bolin 1960) and therefore contains the main gas concentration difference at the ocean-air interface.

The averaged temperature difference across the cool skin of the ocean can be defined as follows from $\mathrm{Ku}$ dryavtsev and Luchnik (1979):

$$
\Delta \bar{T}=\int_{0}^{\infty} p(t) t^{-1}\left(\int_{0}^{t} \Delta T\left(t^{\prime}\right) d t^{\prime}\right) d t
$$

where $p(t)$ is the probability density for time periods $t$ of bursting motions in the molecular sublayers; that is, the probability of local destruction of the molecular sublayers in a time interval $(t, t+d t)$ where $t$ is the elapsed time since the previous destruction.

The averaged surface gas flux can be defined analogously:

$$
\vec{G}_{0}=\int_{0}^{\infty} p(t) t^{-1}\left(\int_{0}^{t} G_{0}\left(t^{\prime}\right) d t^{\prime}\right) d t .
$$

Experiments by Rao et al. (1971) on the structure of the boundary-layer turbulence indicated that the time between bursts is distributed according to a log-normal law. The probability density for such a process is given by

$$
\begin{aligned}
p(t)=(\pi)^{-1 / 2}(\sigma t)^{-1} \exp \left(-(\ln t-m)^{2} / \sigma^{2}\right) & \\
t & >0
\end{aligned}
$$

where $m$ is the mean value of $\ln t$ and $\sigma^{2}$ the variance for the logarithm of the random variable $t$. By use of Eq. (14), we obtain from (11)-(13)

$$
\begin{aligned}
K & =2 \pi^{-1 / 2} \exp \left(3 \sigma^{2} / 16\right)\left(t_{*} / \mu\right)^{-1 / 2}, \\
\Delta \bar{T} & =\left(4 \pi^{-1 / 2} / 3\right) \exp \left(-\sigma^{2} / 16\right)\left(t_{*} / \kappa\right)^{1 / 2} q_{0},
\end{aligned}
$$

where $K=\bar{G}_{0} / \Delta C$ is the gas transfer coefficient, and $t_{*}=\exp \left(m+\sigma^{2} / 4\right)$ is the mean time between bursts. The spatial scale of bursting motions is apparently restricted from below by the internal scale of turbulence (Csanady 1990). Both the thermal and the diffusion sublayers are much thinner than the smallest eddies. Therefore, our model assumes the bursting motions to affect the thermal and diffusion sublayers in the same manner and the quantity $\sigma$ in (15) to have the same value as the quantity $\sigma$ in (16). Furthermore, assuming different quantities $\sigma$ in (15) and (16) actually would result only in different quantities of the nondimensional coefficients in (15) and (16). However, this cannot change the final parameterizations because all the coefficients will be determined empirically from field data.

We consider three wind speed regimes:

I) Calm and low wind speed conditions (the wind speed at a height of $10 \mathrm{~m}, u_{10} \approx 0-5 \mathrm{~m} \mathrm{~s}^{-1}$ ). The cyclic injections of fluid from the molecular sublayer are of convective nature. The time period of the injections is defined by Foster (1971):

$$
t_{\kappa}=C_{\kappa}\left(\nu / \alpha g q_{0}\right)^{1 / 2},
$$

where $C_{\kappa}$ is a dimensionless constant.

II) Moderate wind speed conditions $\left(u_{10} \approx 5-10\right.$ $\mathrm{m} \mathrm{s}^{-1}$ ). According to Csanady (1990) the most intense surface renewal on a wind-blown surface is caused by viscous surface-stress variations associated with rollers on breaking wavelets. The time period of these variations can be defined as

$$
t_{r}=C_{r} \nu / u_{*}^{2},
$$

where $C_{r}$ is a dimensionless constant.

III) High wind speed conditions $\left(u_{10} \geqslant 10 \mathrm{~m} \mathrm{~s}^{-1}\right)$. Long surface wave breaking suppresses the short wavelets (Banner et al. 1989) and changes the law of the gas transfer at the air-sea interface (Csanady 1990). The main renewal is caused by long surface wave breaking. For fully developed wind waves the time scale of the surface renewal depends on the parameters $u_{*}$ and $g$. A dimensional analysis results in the following relation:

$$
t_{w}=C_{w} u_{*} / g
$$

where $C_{w}$ is a dimensionless constant.

According to Kudryavtsev and Soloviev (1985), the surface Richardson number $\left(R f_{0}\right)$ controls the transition from free (I) to forced (II) convection in the near-surface water. The Keulegan number (Ke) ap- 
parently controls the transition from rollers (II) to longwave breaking (III) in the near-surface ocean. The exposure time $\left(t_{*}\right)$ can then be expressed as

$$
t_{*}=\left\{\begin{array}{c}
C_{\kappa}\left(\nu / \alpha g q_{0}\right)^{1 / 2} \text { at } 0<u_{*} \leqslant\left(-\alpha g q_{0} \nu / R f_{c r}\right)^{1 / 4} \\
C_{r} \nu / u_{*}^{2} \text { at } \\
\quad\left(-\alpha g q_{0} \nu / R f_{c r}\right)^{1 / 4}<u_{*} \leqslant\left(\mathrm{Ke}_{c r} \nu g\right)^{1 / 3} \\
C_{w} u_{*} / g \text { at } u_{*}>\left(\mathrm{Ke}_{c r} \nu g\right)^{1 / 3}
\end{array}\right.
$$

where $R f_{c r}$ and $\mathrm{Ke}_{c r}$ are critical values of surface Richardson number and Keulegan number, respectively.

Combining (15) and (16) with (20) leads to the formulas

$$
\begin{aligned}
\Delta \bar{T} / T_{*} & =\Lambda_{0} \operatorname{Pr}^{1 / 2} F_{1}\left(R f_{0}, \mathrm{Ke}\right), \\
K^{+} & =A \Lambda_{0}^{-1} \mathrm{Sc}^{-1 / 2} F_{1}\left(R f_{0}, \mathrm{Ke}\right)^{-1},
\end{aligned}
$$

where $T_{*}=q_{0} / u_{*}, \operatorname{Pr}=\nu / \kappa, A=\left(8 \pi^{-1} / 3\right) \exp \left(\sigma^{2} /\right.$ 8), $\Lambda_{0}=\left(4 \pi^{-1 / 2} / 3\right) \exp \left(-\sigma^{2} / 16\right) C_{r}^{1 / 2}$, and

$$
F_{1}\left(R f_{0}, \mathrm{Ke}\right)=\left\{\begin{array}{c}
\left(R f_{0} / R f_{c r}\right)^{-1 / 4} \text { at }\left|R f_{0}\right| \geqslant\left|R f_{c r}\right| \\
1 \quad \text { at } \\
\left|R f_{0}\right| \leqslant\left|R f_{c r}\right| \text { and } \mathrm{Ke} \leqslant \mathrm{Ke}_{c r} \\
\left(\mathrm{Ke} / \mathrm{Ke}_{c r}\right)^{1 / 2} \text { at } \mathrm{Ke}>\mathrm{Ke}_{c r}, \quad(23)
\end{array}\right.
$$

where $R f_{c r}=-\left(C_{\kappa} / C_{r}\right)^{2}, \mathrm{Ke}_{c r}=C_{r} / C_{w}$.

Expressions (21) and (22) for heat and gas transport at the air-sea interface happen to be closely related. This is not surprising because both the gas transfer and the heat exchange in molecular sublayers are governed by similar laws.

Estimates of $\Lambda_{0}$ and $R f_{c r}$ have been made by Kudryavtsaev and Soloviev (1985) on the basis of Grassl's (1976) cool skin data: $\Lambda_{0}=13.3$ and $R f_{c r}=-1.5$ $\times 10^{-4}$. An estimate of the critical value $\mathrm{Ke} \approx 0.18$ can be obtained from the definition of the Keulegan number, $\mathrm{Ke}=u_{*}^{3} / g \nu$, and from the critical wind speed, $u_{10} \approx 10 \mathrm{~m} \mathrm{~s}^{-1}$, at which, according to the visual Beaufort scale, long-wave breaking sets in [where $u_{*}$ $=u_{10} c_{16^{1}}\left(\rho_{a} / \rho\right)^{1 / 2}, c_{10}$ is the drag coefficient, $\rho_{a}$ is the air density, and $\left.\nu=1.2 \times 10^{-6} \mathrm{~m}^{2} \mathrm{~s}^{-1}\right]$.

For convenience in practical use we truncate (23) in the following way:

$$
\begin{aligned}
& F_{1}\left(R f_{0}, \mathrm{Ke}\right) \\
& \quad \approx\left(1+R f_{0} / R f_{c r}\right)^{-1 / 4}\left(1+\mathrm{Ke} / \mathrm{Ke}_{c r}\right)^{1 / 2} .
\end{aligned}
$$

The truncated version of $F_{1}\left(R f_{0}, \mathrm{Ke}\right)$ only slightly differs from the original version (23). Relations (21) and (22) can then be rewritten in the final form:

$$
\begin{aligned}
\Delta \bar{T} / T_{*}=\Lambda_{0} \operatorname{Pr}^{1 / 2}(1+ & \left.R f_{0} / R f_{c r}\right)^{-1 / 4} \\
& \times\left(1+\mathrm{Ke} / \mathrm{Ke}_{c r}\right)^{1 / 2} \\
K^{+}=A \Lambda_{0}^{-1} \mathrm{Sc}^{-1 / 2}(1+ & \left.R f_{0} / R f_{c r}\right)^{1 / 4} \\
& \times\left(1+\mathrm{Ke} / \mathrm{Ke}_{c r}\right)^{-1 / 2}
\end{aligned}
$$

For calm weather conditions (25) and (26) have the following asymptotes:

$$
\begin{aligned}
& \Delta \bar{T}=\Lambda_{0} \operatorname{Pr}^{1 / 2}\left(-\alpha g q_{0} \nu / R f_{c r}\right)^{-1 / 4} \\
& K=A \Lambda_{0}^{-1} \mathrm{Sc}^{-1 / 2}\left(-\alpha g q_{0}^{-2} \nu / R f_{c r}\right)^{1 / 4} .
\end{aligned}
$$

Formula (27) is similar to (2), obtained by Katsaros et al. (1977) for calm weather conditions, and the appropriate nondimensional coefficients are interconnected by $b=\Lambda_{0}\left(-R f_{c r}\right) t / 4$.

For moderate wind speed conditions, parameterizations (25) and (26) reduce to

$$
\begin{aligned}
\Delta \bar{T} & =\Lambda_{0} \operatorname{Pr}^{1 / 2} q_{0} u_{*}^{-1}, \\
K & =A \Lambda_{0}^{-1} \mathrm{Sc}^{-1 / 2} u_{*},
\end{aligned}
$$

being apparently similar to (1) and (3), respectively. The appropriate nondimensional coefficients are interconnected in the following way: $\lambda=\Lambda_{0} \mathrm{Pr}^{-1 / 2}$ and $\gamma=A \Lambda_{0}^{-1}$.

For high wind speed conditions, (25) and (26) have the following asymptotes:

$$
\begin{aligned}
& \Delta \bar{T}=\Lambda_{0} \operatorname{Pr}^{1 / 2}\left(\nu g \mathrm{Ke}_{c r}\right)^{-d / 2} q_{0} u_{*}^{1 / 2},
\end{aligned}
$$

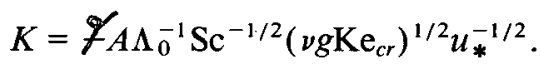

For high wind speeds there are no previous parameterizations of the temperature difference across the cool skin and the gas transfer coefficient. At high wind speed conditions, bubble production in white caps can substantially affect the air-sea gas exchange. According to Woolf and Thorpe (1991) the traditional equation for describing the net air-sea flux, $G_{0}=-k\left(C_{a}-C_{w}\right)$, should be modified to the form,

$$
G_{0}=-k\left[C_{a}\left(1+\Delta_{e}\right)-C_{w}\right],
$$

where $C_{a}=s p_{a}, s$ is the solubility of the gas, $p_{a}$ the partial pressure of the gas, and $C_{w}$ the gas concentration in the mixed layer of the ocean. The equilibrium fractional supersaturation of the gas resulting from the balance of direct and bubble-mediated transfer (Woolf and Thorpe 1991),

$$
\Delta_{e}=0.01\left(V / V_{0}\right)^{2}
$$

where $V$ is the wind speed and $V_{0}$ is the reference wind speed; the latter is equal to $7.2 \mathrm{~m} \mathrm{~s}^{-1}$ for nitrogen, 9.0 $\mathrm{m} \mathrm{s}^{-1}$ for oxygen, $9.6 \mathrm{~m} \mathrm{~s}^{-1}$ for argon, and $49 \mathrm{~m} \mathrm{~s}^{-1}$ for carbon dioxide.

Bubble-mediated heat transport is apparently negligible in comparison with the direct one at the oceanair interface due to the low heat capacity of air inside 


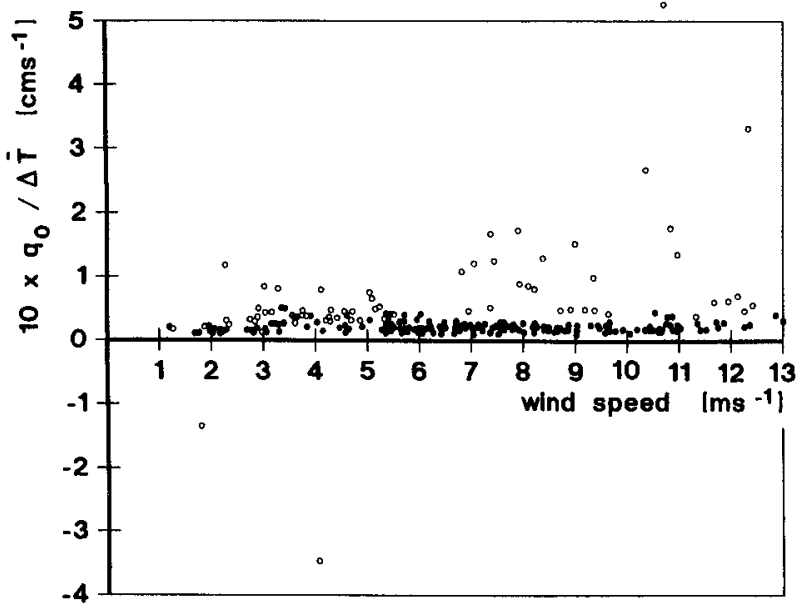

FIG. 1. Dependence of $q_{0} / \Delta \bar{T}$ vs wind speed $u$ according to measurements by Schluessel et al. (1990). Open circles indicate $\Delta \bar{T}$ $\leqslant 0.15 \mathrm{~K}$

the bubbles. At wind speeds greater than about 15-17 $\mathrm{m} \mathrm{s}^{-1}$, droplet and spray production by breaking waves becomes an important mechanism of the air-ocean heat and mass transport (Bortkovskii 1973). However, recent estimates made by Andreas (1992) demonstrate that the spray latent heat flux can be substantial already at wind speeds greater than $10 \mathrm{~m} \mathrm{~s}^{-1}$.

\section{Comparison with experimental data and discussion}

Radiation thermometers may be used to measure the sea surface temperature and thereby the temperature difference across the cool skin (Saunders 1967; McAlister and McLeish 1969; Hasse 1971; Grassl 1976; Paulson and Simpson 1981). Recently, Schluessel et al. (1990) observed the difference between bulk and skin temperature $(\Delta T)$ at different wind and surface heat flux conditions. The nighttime values of hourly mean heat flux $q_{0}$ normalized by simultaneous hourly means of $\Delta T$ (a thermal analog of the gas transfer coefficient) are shown in Fig. 1. The accuracy of the skin temperature measurements by Schluessel et al. (1990) was $\Delta T_{e}=0.05 \mathrm{~K}$. To compare the parameterization (25) with the field data we rejected data with $\Delta \bar{T}$ $\leqslant 0.15 \mathrm{~K}$, that is, data with relative errors greater than or equal to 0.3 (in Fig. 1 these data are drawn as open circles). The rejection criterion was consistent with the estimated error in the heat flux and friction-velocity estimates. According to Fig. 1 the points with $\Delta \bar{T}$ $\leqslant 0.15 \mathrm{~K}$, constituting $32 \%$ of the full nighttime dataset, indeed introduce a large scatter into the "heat transfer coefficient," $q_{0} / \Delta \bar{T}$.

The temperature difference across the cool skin of the ocean was initially parameterized by ascribing a constant value to the nondimensional coefficient $\lambda$ $=\Delta \bar{T} / T_{*}$ (Saunders 1967). Grassl (1976), Wu
(1985), and Schluessel et al. (1990) found that $\lambda$ varied with wind speed. Kudryavtsev and Soloviev (1985) explained the behavior of $\lambda$ at low wind speed conditions by the transition from forced to free convective instability. Parameterization (25), being a generalization of that of Kudryavtsev and Soloviev (1985), includes this effect.

Figure 2 compares averaged nondimensional temperature differences as obtained by Schluessel et al. (1990) with parameterization (25). According to Fig. 2, at low wind speed conditions, parameterization (25) with coefficients $\Lambda_{0}=13.3$ and $R f_{c r}=-1.5 \times 10^{-4}$ [the coefficients obtained by Kudryavtsev and Soloviev (1985) with Grassl's (1976) cool skin data] well describe the experimental data. The parameter $\lambda$ increases from 0 at calm weather conditions to approximately 5 at moderate wind speeds where the slope of the curve slightly decreases. At wind speeds greater than about $u_{10}=7 \mathrm{~m} \mathrm{~s}^{-1}$, the slope is enhanced again. The graph in Fig. 2 is not convenient for an analysis at high wind speeds because (25) also includes the dependence on the Keulegan number.

Figure 3 compares parameterization (25) at $\Lambda_{0}$ $=13.3, R f_{c r}=-1.5 \times 10^{-4}$, and $\mathrm{Ke}_{c r}=0.18$ with hourly mean temperature differences across the cool skin. The mean and rms differences between measured and parameterized temperature differences across the cool skin of the ocean are equal to $-0.03 \mathrm{~K}$ and 0.12 $\mathrm{K}$, respectively. There appear to be some differences between the model prediction and the observations that vary with time. But the mean systematic difference

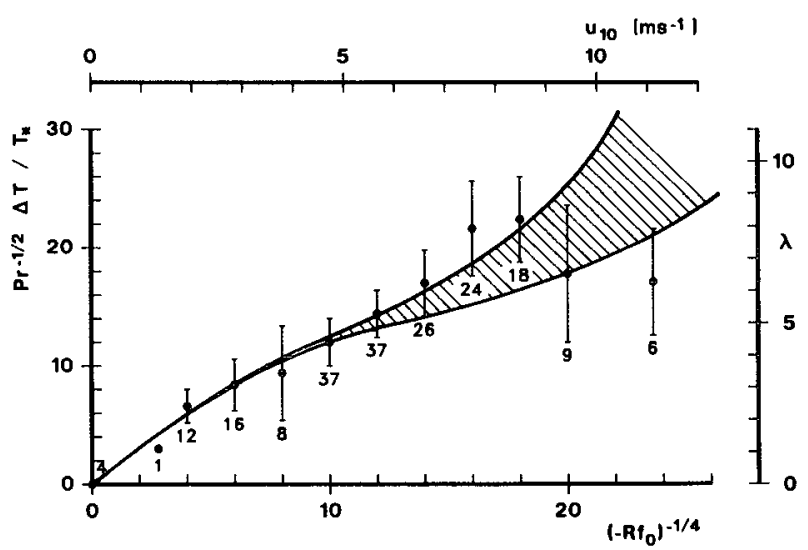

FIG. 2. Plot of averaged values of $\operatorname{Pr}^{-1 / 2} \Delta \bar{T} / T_{*}$ vs $\left(-R f_{0}\right)^{-1 / 4}$. The points are averages over intervals $\Delta\left(-R f_{0}\right)^{-1 / 4}=2$ from $\left(-R f_{0}\right)^{-1 / 4}=3.0$ through $\left(-R f_{0}\right)^{-1 / 4}=24.0$. The point at $\left(-R f_{0}\right)^{-1 / 4}$ $=3.0$ is a single one and the point at $\left(-R f_{0}\right)^{-1 / 4}=24.0$ is an average over the interval $21.0 \leqslant\left(-R f_{0}\right)^{-1 / 4}<27.0$. The vertical bars represent $95 \%$ confidence limits and the numbers below each bar indicate the number of points averaged. Solid curves represent parameterization (25) at two different dynamical temperatures: The lower curve appropriates to $T_{*}=0.003^{\circ} \mathrm{C}$, the upper one to $T_{*}=0.01^{\circ} \mathrm{C}$. Additional coordinates $\lambda$ and $u_{10}$ are plotted for comparison with results from previous papers showing the dependence of the coefficient $\lambda=\Delta T /$ $T_{*}$ on $u_{10}$ at $\operatorname{Pr}=7.3$ and $Q_{0}=-100 \mathrm{~W} \mathrm{~m}^{-2}$. 

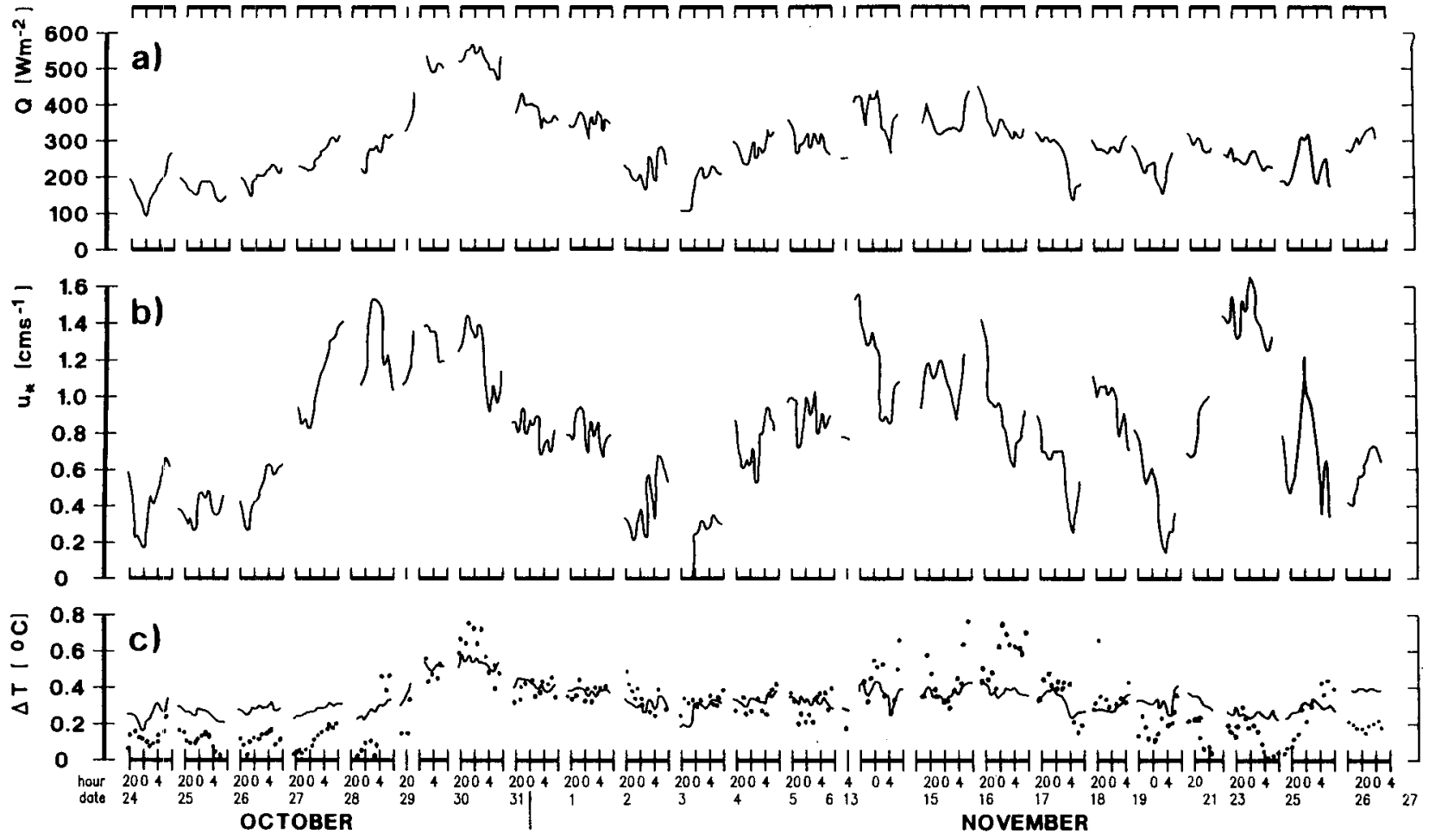

FIG. 3. Comparison of parameterization (25) with nighttime measurements by Schluessel et al. (1990). (a) Hourly means of heat flux through the sea surface, (b) hourly means of friction velocity, (c) hourly means of the difference between bulk and skin temperature during night as observed (points) and parameterized with Eq. (25) (solid lines).

$(-0.03 \mathrm{~K})$ is within the limits of the accuracy of the skin temperature measurements $(0.05 \mathrm{~K})$. Systematic differences that vary with time might be an expression of effects that have neither been accounted for in the experimental setup nor in the parameterization. These could be effects due to a thermal stratification of the upper mixed layer of the ocean between the surface observed by the radiometer and the bulk temperature that was measured at a depth of $2 \mathrm{~m}$. Another but minor factor of uncertainty are horizontal temperature gradients because skin and bulk temperatures were measured at different locations separated by a horizontal distance of about $30 \mathrm{~m}$. The implication for the test of the parameterization is a rather high rms error.

In Fig. 4 the field data on gas transfer coefficient $K$ $=K^{+} u_{*}$ collected by Broecker and Peng (1974), Peng et al. (1979), and Broecker et al. (1986) over almost the entire World Ocean are plotted versus wind speed. Great random scatter of the experimentally obtained values can mainly be explained by problems in gas transfer measurements at varying weather conditions (the procedure was not direct and required stable wind speed conditions during several days of sampling). A comparison of parameterization (26) with field data by Peng et al. (1979) obtained for the well-soluble gas radon under conditions of strong supersaturation results in an estimate of $A \approx 1.85$.
Figure 5 compares data on the "heat" $\left(q_{0} / \Delta \bar{T}\right)$ and gas transfer $(K)$ coefficients with the parameterizations. Due to a lack of original gas transfer datasets, we had no possibility to use a threshold on relative error similar to that used in the analysis of the cool skin data. Therefore, the scatter of points in Fig. 5b is substantially greater than in Fig. 5a. The data analyzed in Fig. 5 are expected to be relevant for comparison with parameterizations (25) and (26). The cool skin data in Fig.

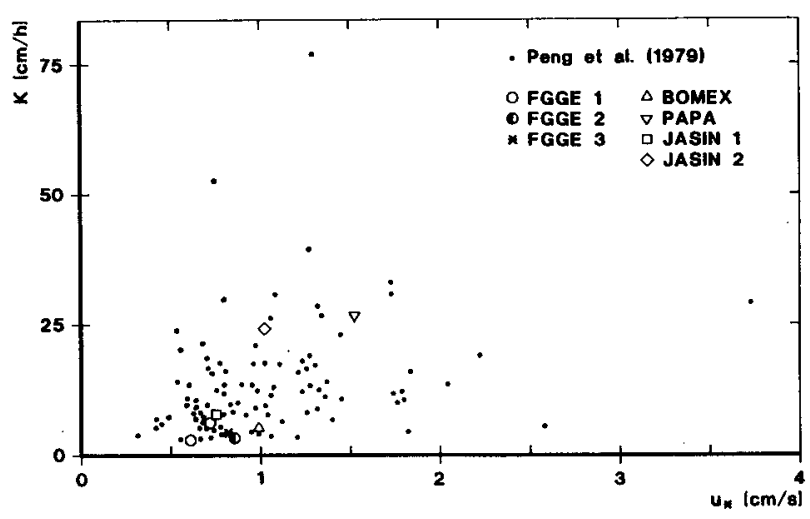

Fig. 4. Gas transfer coefficient vs friction velocity in the upper ocean according to Broecker and Peng (1974), Peng et al. (1979), and Broecker et al. (1986). 

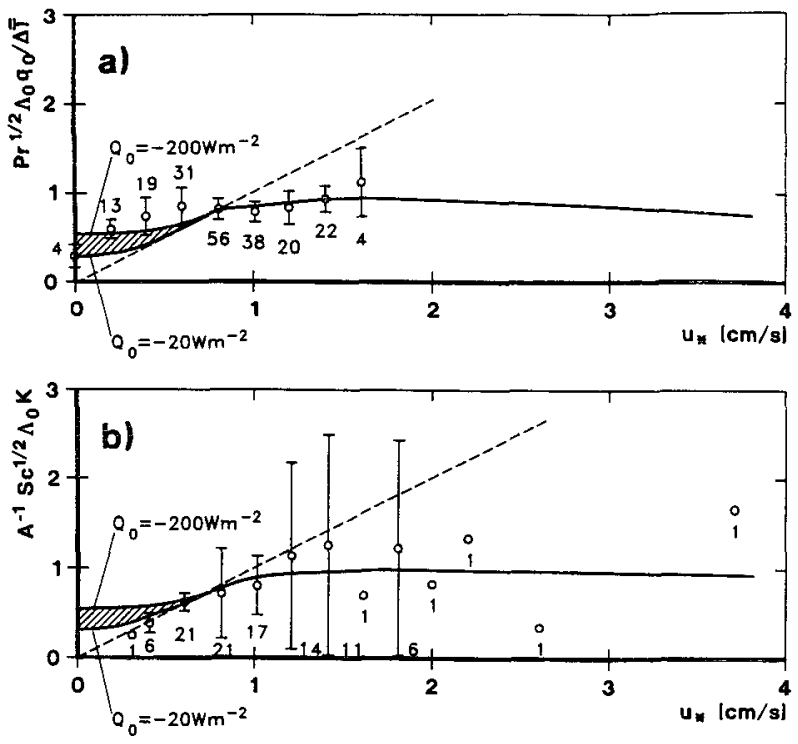

FIG. 5. Comparison of cool skin (a) and gas transfer ( $b$ ) data with universal parameterizations (25) and (26). Solid lines represent the parameterization with different values of heat flux $\left(Q_{0}\right)$ just beneath the sea surface and at $\nu=1.5 \times 10^{-2} \mathrm{~cm}^{-2} \mathrm{~s}^{-1}$. Points are experimental data on the cool skin of the ocean (Schluessel et al. 1990) (a) and on the air-ocean gas transfer coefficient for well-soluble gas radon under conditions of strong supersaturation (Peng et al. 1979) (b). The vertical bars represent $95 \%$ confidence limits and the numbers below each bar are numbers of points averaged. Dashed lines represent the traditional parameterizations (1) and (3).

$5 \mathrm{a}$ are obtained in a wind speed range of $0-13 \mathrm{~m} \mathrm{~s}^{-1}$. Indirect heat transfer due to droplet and spray production is expected to be respectively small in the range of 0-10 $\mathrm{m} \mathrm{s}^{-1}$ (Bortkovskii 1973; Andreas 1992). So the indirect heat transfer can affect only the last right point in Fig. 5a. The gas transfer data in Fig. 5b refer to the well-soluble gas radon under conditions of strong supersaturation, therefore in (33) and (34) $\Delta_{e} \ll 1$ and $C_{a} \ll C_{w}$. Hence, for the data analyzed in Fig. $5 \mathrm{~b}$, the bubble-mediated gas transfer is probably negligible.

According to Fig. 5a, the parameterization (25) is in agreement with the cool skin data. It describes the experimental data more correctly in a wide range of wind speeds than traditional parameterizations. The parameterization (26) with the same coefficients $\Lambda_{0}$ and $R f_{c r}$ (obtained from the cool skin data) is not in contradiction with the gas transfer data. However, at high wind speeds the data on gas transfer appear to be insufficient to draw any conclusions about the validity of the parameterization.

Recently, Watson et al. (1991) determined gas transfer coefficients at high wind speed conditions. Unfortunately, their technique utilizes a poorly soluble gas that does not allow a comparison with our parameterization. According to Woolf and Thorpe (1991) the gas transfer rate for poorly soluble gases can substantially depend upon bubble-mediated transfer processes at high wind speeds.

\section{Conclusions}

Modeling surface renewal results in universal and convenient parameterization for the cool skin of the ocean and air-sea gas transfer. At moderate wind speeds the parameterization agrees with traditional ones. At low wind speed conditions it differs greatly, describing experimental data more correctly. According to parameterizations (25) and (26) at calm weather conditions the "heat" and gas transfer coefficients are nonzero and depend upon the heat flux through the sea surface. At high wind speed conditions (25) and (26) predict a small decrease of the coefficients. This is in agreement with the cool skin data and does not contradict the gas transfer data for the well-soluble gas radon at strong supersaturation. However, at high wind speeds the data do not appear to be fully adequate to test the parameterizations involving only direct heat and gas transfer mechanisms at the air-sea interface. Bubbles and spray produced in breaking waves can increase gas and heat transfer rates at the air-sea interface, thereby raising uncertainty about the validity of the new parameterizations at high wind speeds.

Acknowledgments. We are grateful to G. T. Csanady and to D. K. Woolf for discussions and useful comments on this work. We wish to thank the staff of the Institut für Meereskunde, Kiel, and the crew of the $\mathrm{R} / \mathrm{V}$ Meteor for their assistance in the data collection. The study was financially supported by Deutsche Forschungsgemeinshaft (DFG) and the Bundesministerium für Forschung und Technologie (BMFT). The valuable comments of the reviewers are gratefully acknowledged.

\section{REFERENCES}

Andreas, E. L., 1992: Sea spray and turbulent air-sea heat fluxes. $J$. Geophys. Res., 97, $11429-11441$.

Banner, M. L., I. S. F. Jones, and J. C. Trinder, 1989: Wave number spectra of short gravity waves. J. F/uid. Mech., 198, 321-344.

Bolin, B., 1960: On the exchange of carbon dioxide between atmosphere and sea. Tellus, 12(3), 274-281.

Bortkovskii, R. S., 1973: Air-Sea Exchange of Heat and Moisture during Storms. D. Reidel, 247 pp.

Broecker, W. S., and T. H. Peng, 1974: Gas exchange rates between air and sea. Tellus, 26, 21-35.

- , and Collaborators, 1986: Isotropic versus micro meteorological ocean $\mathrm{CO}_{2}$ fluxes: A serious conflict. J. Geophys. Res., 91, $10517-10527$.

Csanady, G. T., 1978: Turbulent interface layers. J. Geophys. Res., 83, 2329-2342.

,- 1990 : The role of breaking wavelets in air-sea gas transfer. $J$. Geophys. Res., 95, 749-759.

Ebuchi, N., H. Kawamura, and Y. Toba, 1987: Fine structure of laboratory wind-wave surfaces studied using an optical method. Bound-Layer Meteor., 39, 133-151.

Foster, T. D., 1971; Intermittent convection. Geophys. Fluid Dyn., 2, 201-217.

Grassl, H., 1976: The dependence of the measured cool skin of the ocean on wind stress and total heat flux. Bound-Layer Meteor., 10, $465-474$.

Hasse, L., 1971: The sea surface temperature deviation and the heat flow at the sea-air interface. Bound.-Layer Meteor., 1, 368-379. 
- and P. S. Liss, 1981: Gas exchange across the air-sea interface. Tellus, 32, 470-481.

Jähne, B., K. O. Münnich, R. Bösinger, A. Dutzi, W. Huber, and P. Libner, 1987: On the parameters influencing air-water gas exchange. J. Geophys. Res., 92, 1937-1949.

Katsaros, K. B., T. Liu, J. A. Businger, J. E. Tillman, 1977: Heat transport and thermal structure in the interfacial boundary layer measured in an open tank of water in turbulent free convection. J. Fluid Mech., 83, 311-335.

Kim, H. T., S. J. Kline, and W. C. Reynolds, 1971: The production of turbulence near a smooth wall in a turbulent boundary layer. J. Fluid Mech., 50, 139-160.

Kudryavtsev, V. N., and G. L. Luchnik, 1979: On thermal state of the cool skin. Proc. Mar. Hydrophys. Inst., 3, 105-112.

_- , and A. V. Soloviev, 1981: On thermal state of the ocean surface. Izv. Acad. Sci., USSR, Atmos. Oceanic Phys., 17, 1065-1071.

$\ldots$ - and $-1985:$ On the parameterization of the cold film on the ocean surface. Izv. Acad. Sci., USSR, Atmos. Oceanic Phys., 21, 177-183.

Liu, W. T., and J. A. Businger, 1975: Temperature profile in molecular sublayer near the interface of a fluid in turbulent motion. Geophys. Res. Lett., 2, 403-404.

McAlister, E. D., and W. McLeish, 1969: Heat transfer in the top millimeter of the ocean. J. Geophys. Res., 74, 3408-3414.

McLeish, W., and G. E. Putland, 1975: Measurements of wind-driven flow profiles in the top millimeter of water. J. Phys. Oceanogr., 5, 515-518.

Okuda, K., 1982: Internal flow structure of short wind waves. I. On the internal vorticity structure. J. Ocean. Soc. Japan, 38, 2842.

Paulson, C. A., and J. J. Simpson, 1981: The temperature difference across the cool skin of the ocean. J. Geophys. Res., 86, 11 04411054.
Peng, T. H., W. S. Broecker, G. G. Matheieu, Y. H. Li, and A. E. Bainbrige, 1979: Radon evasion rates in the Atlantic and Pacific Oceans as determined during GEOSECS program. J. Geophys. Res., 84, 2471-2486.

Rao, K. N., R. Narashimhia, and B. Narayanan, 1971: The "bursting" phenomenon in a turbulent boundary layer. J. Fluid Mech., 48, 339-352.

Saunders, P. M., 1967: The temperature at the ocean-air interface J. Atmos. Sci., 24, 269-273.

Schluessel, P., W. J. Emery, H. Grassl, and T. Mammen, 1990: On the bulk-skin temperature difference and its impact on satellite remote sensing of sea surface temperature. J. Geophys. Res., 95, $13341-13356$.

Soloviev, A. V., 1987: Day-time heating of the thin surface ocean layer. Mar. Hydrophys. J., 6, 3-12.

_ 1991: Parameterization of the ocean-air gas transfer. Ann. Geophys., 9(Suppl.), 149.

Toba, Y., 1985: Wind waves and turbulence. Recent Studies in Turbulent Phenomena, T. Nasty, H. Marino, and H. Takami, Eds., Association of Scientific Document Information, 277-296.

Watson, A. J., R. C. Upstill-Goddard, and P. S. Liss, 1991: Air-sea gas exchange in rough and stormy seas measured by a dualtracer technique. Nature, 349, 145-147.

Woolf, D. K., and S. A. Thorpe, 1991: Bubbles and the air-sea exchange of gases in near-saturation conditions. J. Mar. Res., 49, 435-466.

Wu, J., 1975: Wind-induced drift currents. J. Fluid Mech., 68, 4970.

- 1984 : Viscous sublayer below a wind-disturbed water surface. J. Phys. Oceanogr., 14, 138-144.

- 1985: On the cool skin of the ocean. Bound-Layer Meteor., 31, 203-207. 